\title{
Copepod foraging in patchy habitats and thin layers using a 2-D individual-based model
}

\author{
Andrew W. Leising* \\ University of Washington, School of Oceanography, Box 357940, Seattle, Washington 98195-7940, USA
}

\begin{abstract}
Evidence has shown that thin, horizontally extending phytoplankton layers may be comprised of smaller high-concentration aggregations of phytoplankton, rather than a homogeneous high-concentration sheet. A 2-D (horizontal and vertical dimensions) individual-based model of copepod foraging was developed, in order to examine whether the foraging success of a copepod would be significantly affected by phytoplankton patchiness. The foraging rules for the simulated copepods were to decrease speed and increase turning angle when high food concentrations are encountered. The underlying distributions of phytoplankton used in the model were, for the patchy layer scenario, representations of raw 2-D field fluorescence obtained using the Optical Serial Section Tomography (OSST) device, and for the homogeneous layer scenario, distributions created by simulated vertical sampling of the OSST distributions with a CTD/Fluorometer. In both the patchy and homogeneous layer scenarios, the copepods always had higher net foraging efficiency than randomly behaving controls, suggesting that the simple behavioral rules adopted are advantageous for copepod-like organisms. Foraging efficiency was significantly greater for the patchy layer scenarios than for the homogeneous layer scenarios when patches were small (i.e. one step length in width) and intense (i.e. near ingestion-saturating concentrations). Ingestion was up to $30 \%$ higher in the most patchy case versus its paired homogeneous case, suggesting that the existence of patchiness is critical to copepod survival, and that sampling scales should not exceed the step length of a copepod.
\end{abstract}

KEY WORDS: Acartia · Foraging · Area-restricted search $\cdot$ Thin layers $\cdot$ Copepods $\cdot$ Individual-based model

\section{INTRODUCTION}

Free-living planktonic herbivorous copepods depend upon phytoplankton for food. Finding phytoplankton is not necessarily easy, as it is patchily distributed throughout the water column at many scales: $O(10 \mathrm{~m})$ (Cullen \& Eppley 1981), $O(1 \mathrm{~m})$ (Bjornsen \& Nielsen 1991), $O(0.1 \mathrm{~m})$ (Owen 1989, Cowles et al. 1993), $O(1 \mathrm{~cm})$ (Cassie 1959, McAlice 1970, Derenbach et al. 1979, Mitchell \& Fuhrman 1989, Owen et al. 1992, Tiselius et al. 1994). In some cases, subsurface chlorophyll maxima consist of smaller-scale features of several localized minima and maxima on a scale of

*E-mail: aleising@ocean.washington.edu
$O(10 \mathrm{~cm})$ in the vertical dimension (Cowles et al. 1993). These smaller features may span a range of chlorophyll concentrations that may be limiting through to satiating for copepods. The patches themselves extend horizontally for $O(10 \mathrm{~km})$ and can last for $O(10 \mathrm{~h})$, and have been labeled 'thin layers' (Cowles et al. 1993). Some species of copepods, which, when vertically migrating, can easily travel $O(10 \mathrm{~m})$ in a $O(10 \mathrm{~min})$, and $O(100 \mathrm{~m})$ over the course of $1 \mathrm{~d}$, should encounter these thin layers repeatedly within their normal foraging ambit. The impact of these features on the feeding and growth of copepods, and the foraging strategies that copepods might use to exploit thin layers are presently unknown.

The difficulty in assessing the impact of thin layers on copepod growth arises from the current inability to 
sample copepods in situ on the same scale as the patchiness of the phytoplankton, or to follow individuals as they move within and between patches of food. This leaves modeling or laboratory studies as alternative methods for studying the impacts of microscale patchiness on copepod growth. Laboratory work has indicated that the existence of thin layers of food (i.e. patches) may significantly increase the growth of Acartia tonsa, as measured by either egg or fecal production rate (Tiselius 1992, Saiz et al. 1993). However, it is difficult to 'scale up' laboratory results obtained in small vessels to the field because the size of the vessels usually restricts the movement of the copepods over anything but the shortest time scales of observation, i.e. $O(10 \mathrm{~s})$ to $O(10 \mathrm{~min})$. Modeling studies can provide a way to examine the motions of copepods over any spatial or temporal scale, although they have the drawback that they are only as realistic as their inputs. In a modeling study, Tiselius et al. (1993) simulated the foraging of copepods for distributions of food that were horizontally homogeneous and vertically heterogeneous, i.e. thin layers. They found that as the degree of patchiness-defined as the relative difference between the concentration of food within a layer versus the average background concentration-changed, there was an impact on both growth and predation risk for the copepods. It was concluded that having a strong behavioral reaction to patchiness in the copepods' swimming behavior was more beneficial for avoiding predation than increasing ingestion. This may have resulted because the swimming behavior of their model copepods reacted in the same way to all patches of food above a minimum threshold concentration, although their ingestion rates would vary between these patches. Thus it is unclear from their study whether thin layers have an appreciable effect on growth rates, or whether their result was specific to the foraging strategy that was chosen.

New evidence concerning the structure of thin layers themselves is further confounding discussion of the importance of these layers on the feeding of planktonic copepods. In a field study, Jaffe et al. (1998), used a noninvasive camera system with a visual field in the vertical plane of $\sim 70 \times$ $70 \mathrm{~cm}$ and a resolution of $\sim 7 \times 7 \mathrm{~mm}$; they found that what appeared to be thin, continuous horizontal layers as measured by a fluorometer-equipped CTD, were actually comprised of small
$O(1 \mathrm{~cm})$ isotropic patches (Fig. 1). Thus, there may be times when thin layers are not of uniform concentration in the horizontal direction. If these images are accurate representations of thin layers, there could be important implications for both the grazing and foraging behavior of planktonic herbivorous copepods. First, copepods must find depths at which these highconcentration patches (i.e. the thin layers) exist, and then they must forage both horizontally and vertically to find the smaller individual patches which comprise the horizontal 'layer'. This implies that copepods need foraging strategies that will function over multiple spatial scales, if patchy thin layers are a regular feature of their planktonic environment. It is unclear how often layers are not horizontally homogeneous, and additional sampling of microscale phytoplankton distributions is needed.

In the present study, an individual-based simulation model (Leising 2000) was used to examine the impact of different dimensionalities of thin layer patchiness on the foraging success of planktonic copepods. The simulated copepods were given a correlated random walk as their foraging behavior, which is essentially an 'area-restricted search' (Tinbergen et al. 1967), where a forager takes shorter step lengths and turns at greater angles between steps as the density of prey increases. This behavior is somewhat different than the behavior used by Tiselius et al. (1993) as in the cur-
A

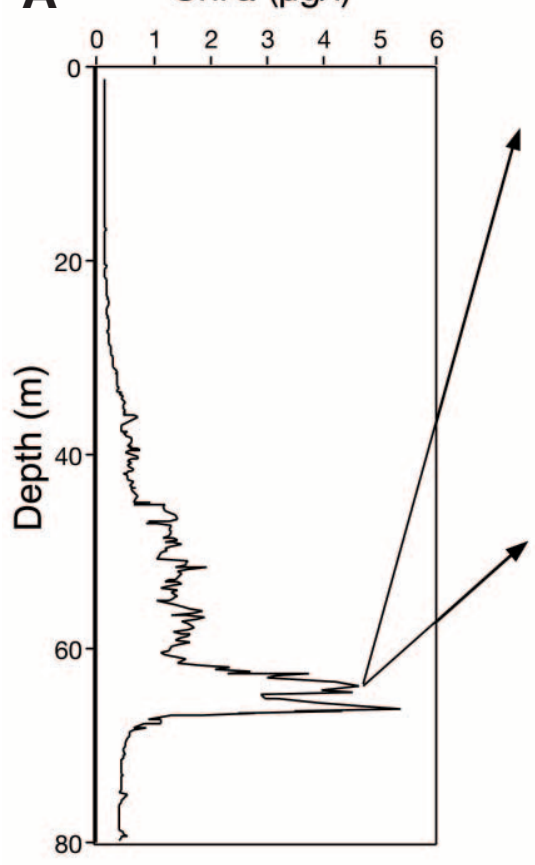

B

Fig. 1. (A) Chlorophyll vs depth (Seabird SBE-19 CTD with Wetlabs WetStar fluorometer). (B) Chlorophyll at depth $\approx 64 \mathrm{~m}$ (Optical Serial Section Tomography data). Image size $\approx 70 \times 70 \mathrm{~cm}$, resolution $100 \times 100$ pixels (Jaffe et al. 1998, Leising 2000) 
rent model the behavioral response of the copepods varies in proportion with the strength of the stimulus, i.e. the concentration of food. The main questions that these simulations attempt to address are: (1) Is there a large impact on copepod feeding when thin horizontal layers are themselves made up of smaller patches? and (2) What effect, if any, does the choice of a particular functional (i.e. swimming) response have on the foraging success of the copepods in these various thin-layer environments?

\section{MATERIALS AND METHODS}

Model description. The model used for this study was a FORTRAN77 version of a MATLAB simulation

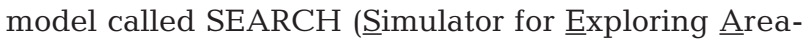
Restricted search in Complex Habitats) (Leising 2000) In general, the copepods move around in a 2 dimensional grid that has reflecting boundaries at the top and bottom, and wrap-around boundaries on the sides. The 'area-restricted search' behavior, defined in the 'Introduction', was chosen because it has been seen to result in aggregation into areas of higher food resources in other animals, including insects (Karieva 1982, Karieva \& Odell 1987, Ferran \& Dixon 1993), birds (Tinbergen et al. 1967, Smith 1974, Zach \& Falls 1977), and mammals (Benedix 1993, Cassini \& Föger 1995, Haskell 1997). Some copepods have been observed to decrease their swimming speed or decrease their frequency of 'hop' or 'jump' behavior when encountering higher food concentrations, and may also turn at greater angles, a characteristic of arearestricted search behavior (Pseudocalanus minutus, Buskey 1984; Oithona davise females, Uchima \& Hiramo 1988; Temora longicornus and Pseudocalanus elongans, Tiselius \& Jonsson 1990; Acartia tonsa females, Tiselius 1992).

The model is only briefly summarized here, as a detailed description of how the model works has been published elsewhere (Leising 2000). At each time-step, each individual copepod moves a particular step length $S_{l}$ defined as the straight line distance traveled before being allowed the possibility of turning. It may differ from swimming speed, i.e. the time taken to travel a set distance, depending on the distance over which swimming speed is calculated. Step length $S_{l}$ is determined by the concentration of food $C$ within the grid space where the animal is located:

$$
S_{1}=S_{\max }\left(1-C /\left[k_{\mathrm{sv}}+C\right]\right)
$$

where $k_{\mathrm{sv}}$ is the 'half-saturation constant' of step length response, and $S_{\max }$ is the maximum step length allowed (Fig. 2A). This function is asymptotic towards zero at high concentrations, and is essentially a modi-
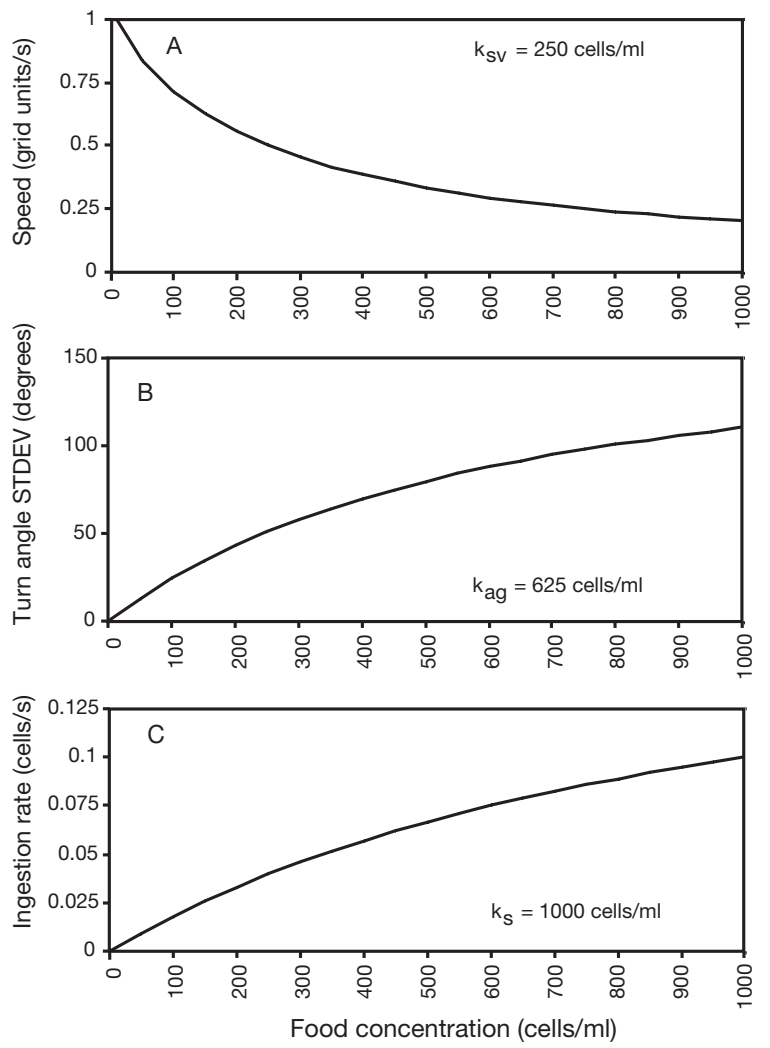

Fig. 2. Variation of forcing functions with food concentration: (A) step length; (B) standard deviation of turn angle probability density function; $(\mathrm{C})$ ingestion rate

fied Holling Type-II response (Holling 1966). This formulation was chosen since it reflects what is known from the small amount of data concerning copepod step lengths versus food concentration (Piontkovskii \& Petipa 1976). Before moving forward at each time-step, the simulated copepod turns. The probability of each particular turn angle is taken from a Gaussian distribution with the previous heading providing the mean, and the standard deviation $A_{\text {std, }}$ varying with the underlying concentration of food $C$ :

$$
A_{\text {std }}=A_{\max } C /\left(k_{\mathrm{ag}}+C\right)
$$

where $k_{\mathrm{ag}}$ is the half-saturation constant for turning angle, and $A_{\max }$ is the maximum allowed standard deviation of the probability density function for turning angle (PDF; Fig. 2B). For animals with anterior-posterior polarization, bilateral symmetry, and which therefore exhibit a tendency to continue in the direction they are already heading (e.g. copepods), this function should mimic such movement (Bovet \& Benhamou 1988). This function has the property that at food concentrations that are low compared to the turning angle half-saturation constant, the copepod will have a high probability of continuing in a straight line. Conversely, 
when $A_{\max }$ is large (e.g. $180^{\circ}$ for the current study), and the concentration of food is large compared to the turning angle half-saturation constant, turn angles after each step will be virtually uncorrelated with the previous heading; thus complete reversals of direction are possible between each time-step.

Once a copepod has turned and moved, it will eat phytoplankton at its new location, with an ingestion rate described by a Michaelis-Menten style equation:

$$
I=I_{\max } C /\left(k_{\mathrm{s}}+C\right)
$$

where $I_{\max }$ is the maximum ingestion rate of cells, $k_{\mathrm{s}}$ is the half-saturation constant for feeding, and $C$ is the concentration of food (Fig. 2C). Laboratory data on the feeding of copepods suggests that this equation is a fair representation of ingestion rate (e.g. Mullin et al. 1975). No satiation response was included in the model, although over longer time periods, the copepods might be expected to fill their guts.

Foraging environment. The foraging arena was set to 50 units wide, by 500 units high. For copepods, the units will correspond to $\mathrm{cm}$, making the foraging arena $50 \mathrm{~cm}$ wide by $5 \mathrm{~m}$ high. Horizontally, the copepods and food patches wrap around (i.e. copepods that swim off of one side, re-enter the environment on the other side, with no change in heading from their point of view), while vertically, the boundaries are reflecting (i.e. copepods reaching the top or bottom 'bounce' off the surface at $90^{\circ}$ to their previous heading). These boundary conditions were chosen to reflect the idea that in nature, copepods can affect their vertical position relative to the small-scale distribution of their food at a scale of $O(10 \mathrm{~m})$; however, they cannot easily affect their horizontal position relative to the size of a horizontal layer with a potential scale of $O(10 \mathrm{~km})$. Thus the copepods will experience the smallest scale patchiness of $O(1 \mathrm{~cm})$ in both the vertical and horizontal direction, but will experience larger scale patchiness of $O(1 \mathrm{~m})$ in the vertical dimension only.

The phytoplankton patch structure was created as a vertical series of horizontally extending layers, in which the layers themselves were comprised of smaller patches. These smaller individual patches had a radially symmetric Gaussian distribution of phytoplankton concentration in cross section. The density of patches throughout the entire foraging arena (npatches) was set at 375 patches per $10^{4} \mathrm{~cm}^{-2}$, while the maximum density of phytoplankton within the individual patches that comprise a layer varied as a function of depth. This patch density is close to $1 / 2$ of the patch density shown in the 2-D OSST image of Fig. 1, and is similar to the patch density that was found at areas adjacent to the chlorophyll maximum during that study (Jaffe et al. 1998). The maximum concentration of phytoplankton versus depth within these smaller patches was set by a
Gaussian probability density function with its mean at the vertical center of the water column and its standard deviation as $1 / 4$ the vertical height of the arena, such that the maximum concentration within patches was near the vertical center of the water column. The horizontally-extending layers were then created by adding a sine wave, with wavelength $100 \mathrm{~cm}$ and amplitude 100 cells $\mathrm{ml}^{-1}$, to the vertical control of the maximum concentration of phytoplankton within individual patches. The wavelength of $100 \mathrm{~cm}$ was chosen because it results in 5 layers extending for approximately $50 \mathrm{~cm}$ in the vertical, with $50 \mathrm{~cm}$ spaces in between containing little, if any, phytoplankton. These spatial scales are similar to the range of thin layer scales that have been previously measured $(\sim 10$ to $50 \mathrm{~cm}$, reviewed in Cowles et al. 1998). The resulting maximum concentration of phytoplankton within an individual patch versus depth is shown in Fig. 3.

Two different patchy environment cases were then created by altering the standard deviation of the Gaussian cross-sectional density of the individual patches. In case A (Fig. 4A), the standard deviation of the smaller individual patches (pstdev) was set to $0.5 \mathrm{~cm}$, and in case B (Fig. 5A), it was set to $2 \mathrm{~cm}$. With pstdev $=0.5$, the distance between \pm 1 standard deviation of the Gaussian cross-sectional density of a patch

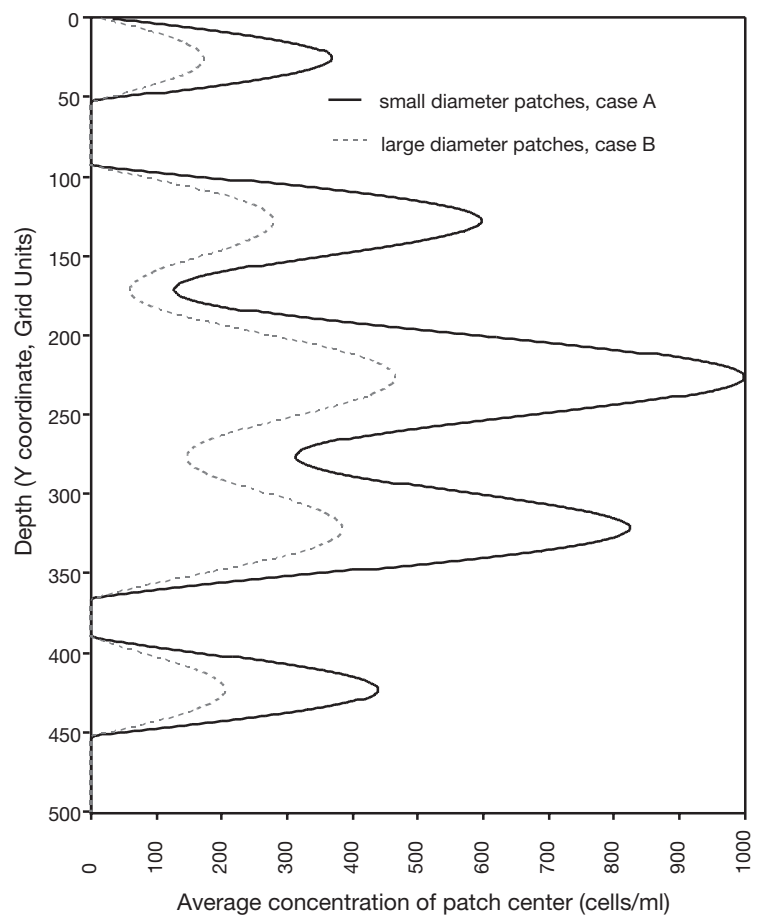

Fig. 3. Effect of vertical variation of conc parameter on average cell concentration at center of patch. Structure created by combining a sine wave (amplitude 100 conc units, wavelength 100 grid units) with a Gaussian distribution (mean $y=$ $250, \mathrm{SD}=125$ grid units). Solid line, pstdev $=0.5$ grid units (case A); dashed line pstdev $=2$ grid units (case B) 


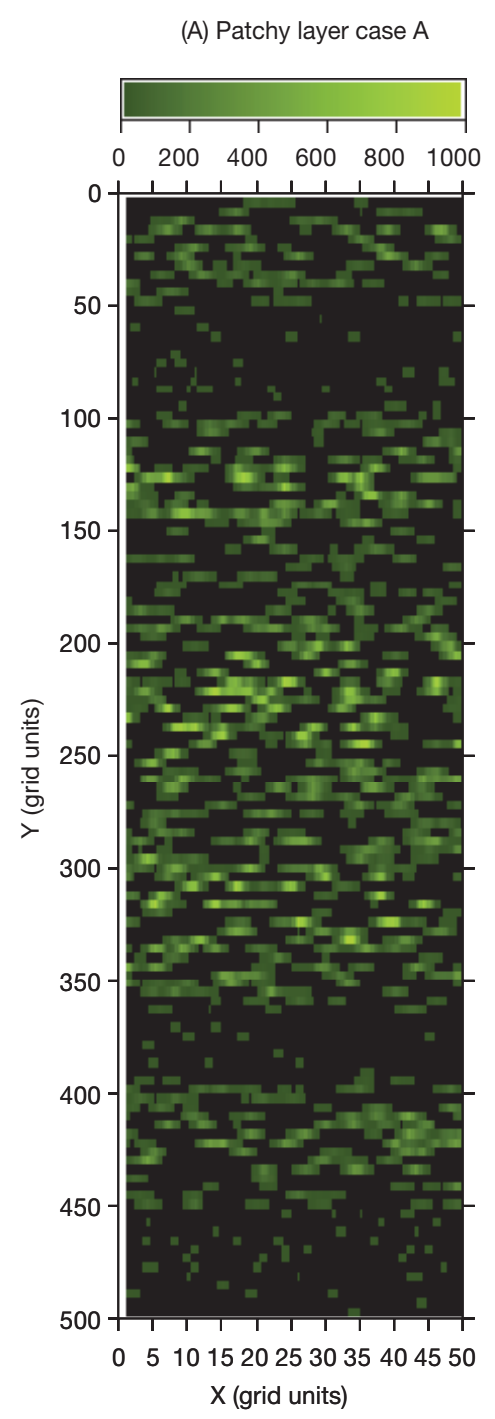

(B) Homogeneous layer case $A$ (simulated CTD cast through A)
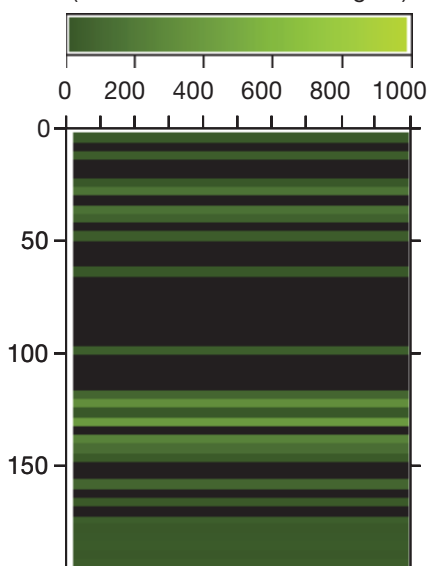

$200-$
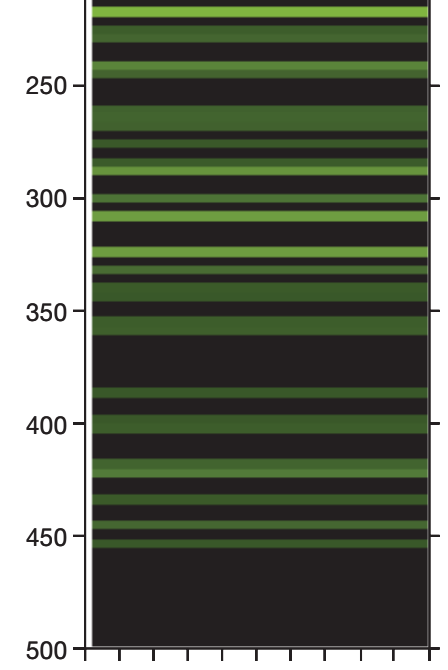

$0 \quad 5101520253035404550$ $\mathrm{X}$ (grid units)

Fig. 4. Case A: (A) heterogeneous layer scenatio (npatches $=$ 375 per $10^{4}$ grid units ${ }^{2}$, pstdev $=0.5$ grid units), and (B) homogeneous layer scenatio (patches in the vertical dimension only)

(which will be referred to as the standard width of a patch) is the same as the maximum step length of the simulated copepods, $S_{\max }$ of $1 \mathrm{~cm}$ per time-step. In case $\mathrm{B}$, the standard patch width was $4 \times S_{\max }$. The overall result of these settings is that the 'intensity' of individual patches is greater in case A because the individual patches are narrower, although the total spatially integrated amount of food available is the same in both cases. These patch widths were chosen because they produce patches on the same scale as those observed by Jaffe et al. (1998); patches are 1 to $5 \mathrm{~cm}$ wide, with similar sized spaces in between containing little or no phytoplankton.

To estimate the effects of patchy thin layers versus homogeneous thin layers, horizontally homogeneous layers were created separately for both case A and
(A) Patchy layer case B
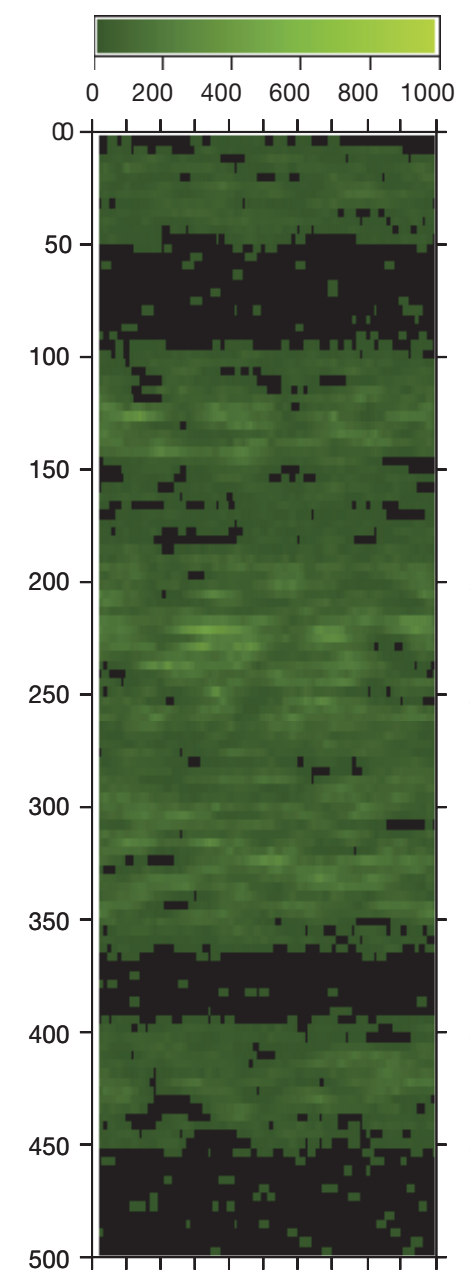

$0 \quad 5101520253035404550$ $X$ (grid units)
(B) Homogeneous layer case B

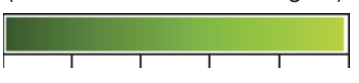

$0 \quad 200 \quad 400 \quad 600 \quad 800 \quad 1000$
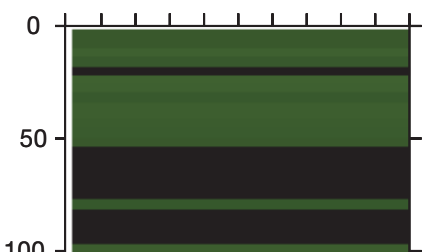

100

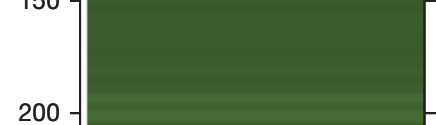

05101520253035404550

$\mathrm{X}$ (grid units) (simulated CTD cast through A)

Fig. 5. Case B: (A) heterogeneous layer scenatio (npatches $=$ 375 per $10^{4}$ grid units ${ }^{2}$, pstdev $=2.0$ grid units), and (B) homogeneous layer scenatio (patches in the vertical dimension only)

case B. This was accomplished by taking the average value of the 3 center-most grid squares horizontally from the above patch cases, and then replacing all grid squares horizontally, for each value of $Y$, with this average. The resulting distribution has structure only in the vertical direction, with a resolution of 1 grid unit (Figs. 4B \& 5B). This structure is intended to be representative of what might be sampled with a CTD equipped with a high-resolution fluorometer. The total integrated number of cells available to be eaten was slightly different in these horizontally homogeneous scenarios due to the averaging procedure; spatially averaged concentration for case A was 50.3 cells ml$^{-1}$, and 49.8 cells ml- ${ }^{-1}$ for its homogeneous approximation (i.e. $1 \%$ lower), and average concentration for case B was 50.4 versus 50.6 cells ml ${ }^{-1}$ for its homogeneous 
approximation (i.e. $<1 \%$ higher). This small difference in total average cell concentration should have little effect, however, since it has a nearly negligible effect on the average concentration within any particular grid square, which is what ultimately affects the responses of the copepods.

Specific foraging behavior. The simulated copepods were given a maximum speed of $1 \mathrm{~cm} \mathrm{~s}^{-1}$. While this seems like a high speed for a copepod, they will only travel at this maximum speed when there is no food present, and this maximum speed is easily within 'hop' or 'jump' speeds that have been observed in the laboratory (Tiselius \& Jonsson 1990, Saiz \& Alcaraz 1992, Leising \& Yen 1997). The maximum ingestion rate was set to 0.2 cells $\mathrm{s}^{-1}$, and the half-saturation constant of the ingestion response, $k_{\mathrm{s}}$, was set to $1000 \mathrm{cells} \mathrm{ml}^{-1}$, which gives ingestion rates similar to those reported by Durbin \& Durbin (1992) for Acartia hudsonica feeding on Thallassiosira constricta. Initial starting locations for copepods were random; however, all copepods started with a heading straight upwards, so that they would all encounter at least 1 patch within the simulation time of $21600 \mathrm{~s}$. As a measure of the foraging success of the copepods, the average number of cells eaten over the length of the simulation and the total distance traveled over the length of the simulation were recorded for each individual copepod. This allowed calculation of the ratio of number of 'cells eaten: distance traveled' (CEDT) for each copepod. The average and standard deviation of CEDT were also calculated for the population. It is hypothesized that as the distance traveled increases, the net gain from food eaten should decrease, if travel costs are not negligible (Morris et al. 1985, Morris et al. 1990) and predation risk increases (Gerritsen \& Strickler 1977).
Model runs. Each run was for 100 copepods and simulated $6 \mathrm{~h}$ with a $1 \mathrm{~s}$ time-step. To examine the effect of varying the parameters $k_{\mathrm{sv}}$ and $k_{\mathrm{ag}}$ controlling the swimming response of the copepod, multiple runs were made for each patchy-layer environment (Figs. 4A \& 5A). For the first set, $k_{\text {ag }}$ was held constant at 250 cells $\mathrm{cm}^{-2}$, and $k_{\mathrm{sv}}$ was either 250,625 or 1000 cells cm$~_{-2}$. For the second set, $k_{\mathrm{sv}}$ was held constant at 250 cells $\mathrm{cm}^{-2}$, and $k_{\mathrm{ag}}$ was either 250,625 , or 1000 cells $\mathrm{cm}^{-2}$. These two sets were then repeated for the homogeneous layer scenarios (Figs. 4B \& 5B). Finally, random speed control simulations were run, to compare with each behavioral run from the patchy layer scenarios. For these control simulations, step length was drawn at random from a uniform distribution at each time-step, regardless of underlying food concentration and the maximum step length was set such that the average distance traveled by the individuals is the same as the average distance traveled in the behavioral simulations; any subsequent difference in CEDT is therefore due to differential feeding. A complete listing of the parameters used to force the SEARCH model are given in Table 1.

\section{RESULTS}

Individuals foraging within case A, whose step length controlling parameter had the highest sensitivity to food concentration $\left(k_{\mathrm{sv}}\right.$ of 250 cells cm$\left.{ }^{-2}\right)$, ate, on average, the highest number of cells compared with any other case (Fig. 6A). For both cases A and B, the average number of cells eaten decreased as step length sensitivity decreased for both patchy and homogeneous layer scenarios (Fig. 6). For patchy layers in both cases A and B,

Table 1. Parameter values used for the SEARCH model

\begin{tabular}{|c|c|c|c|}
\hline Variable & Description & Value & Units \\
\hline time & Number of time-steps for a run & 21600 & $\mathrm{~s}$ \\
\hline $\operatorname{gridx}$ & Grid size in horizontal dimension $(x)$ & 50 & Grids \\
\hline gridy & Grid size in vertical dimension $(y)$ & 500 & Grids \\
\hline pstdev & Standard deviation of patch diameter & $0.5-2$ & Grids \\
\hline npatches & Density of patches & 375 & $10^{4}$ grids $^{-2}$ \\
\hline conc & Number of grid cells filled per patch & 200 & - \\
\hline spotc & Concentration required to fill grid spaces at each iteration & 10 & Cells ml $\mathrm{m}^{-1}$ \\
\hline$C_{\max }$ & Maximum concentration of any single grid space & 1000 & Cells ml ${ }^{-1}$ \\
\hline wlength & Wavelength of sine wave & 100 & Grids \\
\hline amp & Amplitude of sine wave & 100 & Cells ml $\mathrm{m}^{-1}$ \\
\hline$S_{\max }$ & Maximum step length of copepod & 1 & Grids \\
\hline$k_{\mathrm{sv}}$ & Half-saturation constant of step length & $250-1000$ & Cells ml $\mathrm{m}^{-1}$ \\
\hline$A_{\max }$ & Maximum standard deviation of turning angle & 180 & Degrees \\
\hline$k_{\mathrm{ag}}$ & Angle half-saturation constant & $250-1000$ & Cells $\mathrm{ml}^{-1}$ \\
\hline number & Number of copepods & 100 & - \\
\hline$I_{\max }$ & Maximum ingestion rate & 0.2 & Cells ind. ${ }^{-1}$ time-step $^{-1}$ \\
\hline$k_{\mathrm{s}}$ & Half-saturation constant of ingestion response & 1000 & Cells ml ${ }^{-1}$ \\
\hline
\end{tabular}



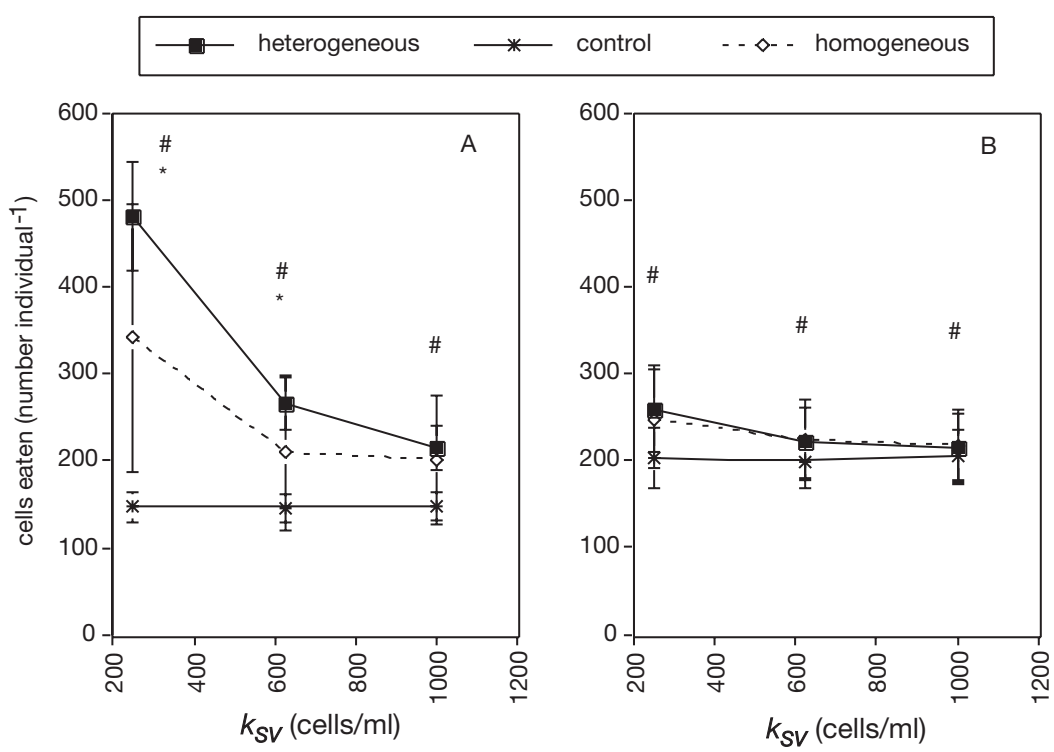

Fig. 6. Mean total cells eaten per copepod $(n=100)$ versus $k_{\mathrm{sv}}$. Error bars $\pm 1 \mathrm{SD}$. $k_{\mathrm{ag}}=250$ cells per grid square. ${ }^{*}$ Significant differences $(\mathrm{p}<0.05$, paired $t$-test with unequal variances) between heterogeneous and homogeneous layers and \# between heterogeneous layer and control

the average number of cells eaten was significantly higher for area-restricted search runs than control runs for any combination of $k_{\mathrm{sv}}$ and $k_{\mathrm{ag}}$ that was run; having a behavioral rule was always better than having none ( $\mathrm{p}<0.05,2$-sample $t$-test for samples with unequal variance-Satterthwaite's method; Figs. 6 \& 7).

For case $\mathrm{A}$, the average number of cells eaten was significantly greater for the patchy layer scenario than the homogeneous layer scenario for any combination of $k_{\mathrm{sv}}$ and $k_{\mathrm{ag}}$, except at the highest $k_{\mathrm{sv}}$ of 1000 cells cm${ }^{-2}$ ( $\mathrm{p}<0.05$, 2 -sample $t$-test for samples with unequal variance-Satterthwaite's method; Figs. 6A \& 7A). For case B, copepods in the patchy layer scenarios did not eat significantly more cells on average than copepods in the homogeneous layer scenarios $(\mathrm{p}>0.05,2$-sample $t$-test for samples with unequal variance-Satterthwaite's method; Figs. 6B \& 7B). It appears that high intensity patches (case A) led to a large difference between the amount of food ingested between the patchy and homogeneous layer scenarios, and little difference when individual patches were not as intense (case B). Within the high intensity patch environment (case A), copepods that had the highest step-length sensitivity ate the most, while varying their turn-angle sensitivity had little effect.
The trends of the results for the calculated CEDT ratio were nearly identical to those for the average number of cells eaten, as was expected since there is an inverse relationship between cells eaten and distance traveled in the model formulation. Distance traveled is not reported here, however, it can be estimated by dividing average CEDT by the average amount eaten for each run. The patchy layer environment (case A), with a $k_{\mathrm{sv}}$ of 250 cells cm $\mathrm{cm}^{-2}$ (i.e. highest sensitivity to food concentration) led to the highest average CEDT (Figs. 8A \& 9A). For both cases A and B, CEDT was less as their step lengths became less sensitive to the underlying concentration of food (i.e. increased $k_{\mathrm{sv}}$ ) (Fig. 8). For both cases A and B, the average CEDT was significantly higher for copepods using area-restricted search within the patchy layer scenario than in any control run, regardless of step-length or turn-angle sensitivity $(\mathrm{p}<0.05$, 2 -sample $t$-test for samples with unequal variance-Satterthwaite's method; Figs. 8 \& 9). For case A, CEDT was significantly greater for the patchy layer scenario than the homogeneous layer scenario, for any combination of $k_{\mathrm{sv}}$ and $k_{\mathrm{ag}}$, except at the highest $k_{\mathrm{sv}}$ of 1000 cells $\mathrm{cm}^{-2}(\mathrm{p}<0.05,2$-sample $t$-test for samples with unequal variance-Satterthwaite's method; Figs. 8A \& 9A). For
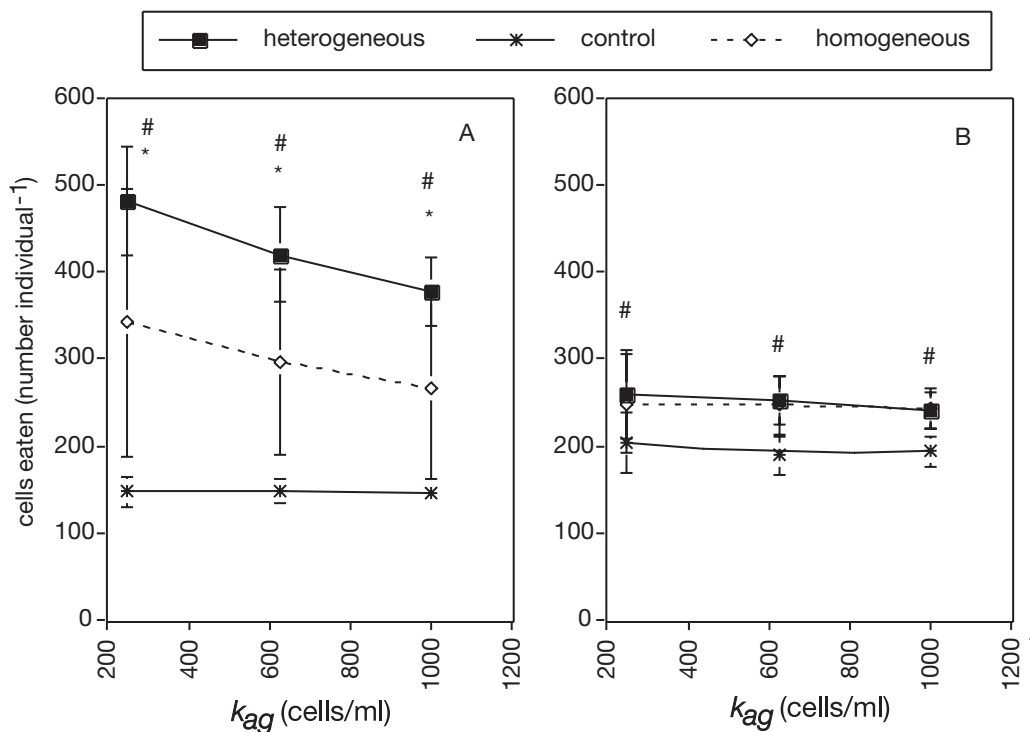

Fig. 7. Mean total cells eaten per copepod $(n=100)$ versus $k_{\text {ag }}$. Error bars \pm 1 SD. $k_{\mathrm{sv}}=250$ cells per grid square. ${ }^{*}$ Significant differences $(\mathrm{p}<0.05$, paired $t$-test with unequal variance) between heterogeneous and homogeneous layers and \# between heterogeneous layer and control 

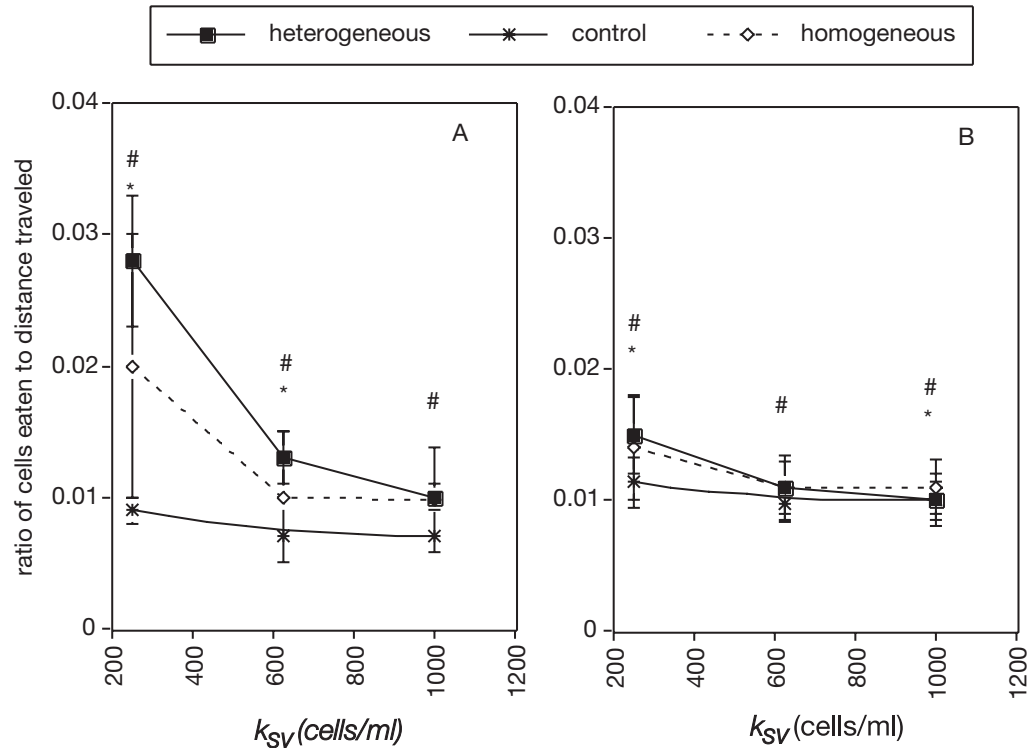

Fig. 8. Mean CEDT (cells eaten: distance traveled) ( $n=100)$ versus $k_{\mathrm{sv}}$. Error bars $\pm 1 \mathrm{SD} . k_{\mathrm{ag}}=250$ cells per grid square. ${ }^{*}$ Significant differences $(\mathrm{p}<0.05$, paired $t$-test with unequal variance) between heterogeneous and homogeneous layers and \# between heterogeneous layer and control case B, CEDT was only significantly higher for the patchy layer scenario than the homogeneous layer scenario when both $k_{\mathrm{sv}}$ and $k_{\mathrm{ag}}$ were at their lowest $\left(250\right.$ cells $\mathrm{cm}^{-2}$ cells/grid unit $\left.{ }^{2}\right)(\mathrm{p}>0.05,2$-sample $t$-test for samples with unequal variance-Satterthwaite's method; Figs. 8B \& 9B). In fact, in case B, at high $k_{\mathrm{sv}}$, the copepods ate significantly more in the homogeneous layer scenario than in the patchy layer scenario ( $p<0.05,2$-sample $t$-test for samples with un-equal variance-Satterthwaite's method; Fig. 7B). Copepods generally ate more and traveled shorter distances in the patchy layers than the homogeneous layer approximations when the patchy layers were intense and when the copepods' step-length sensitivities were high. Turn-angle sensitivity had little effect regardless of the level of patchiness.

Comparing results between patch environments, the the highest values of food eaten and CEDT were found in case A, the 'patchiest' environment. The less patchy case B led to the lowest amount of food eaten, and therefore lower CEDT. With lower maximum concentrations available in case B (see Fig. 3), ingestion rates are also lower; copepods need to spend more time within these lower concentration patches to ingest the same number of cells compared to a patch with a higher concentration. Conversely, patches should be easier to find, since they are 4 times wider, and copepods will therefore spend more time within patches than between patches.

The differences in time spent within and between patches, and the effects of the swimming parameters sensitivities, can best be seen by examining example tracks of individual copepods foraging through the simulated environments (Fig. 10). Fig. 10 shows examples of 4 individual copepods (1 copepod per panel), tracked for 600 s. Fig. 10A,C represent an enlargement of a $50 \times$ $50 \mathrm{~cm}$ portion of patchy layer in case $\mathrm{A}$ (Fig. 4A), while Fig. 10B,D are $50 \times$ $50 \mathrm{~cm}$ portions of patchy layer in case B (Fig. 5A). For illustration purposes, the boundaries wrap around, such that a copepod exiting the left side reappears on the right side of the panel. Fig. 10A,B show copepods that are very sensitive in their swimming functional response $\left(k_{\mathrm{sv}}=250\right.$ and $k_{\mathrm{ag}}=250$ ) while Fig. 10C,D show copepods that are less sensitive $\left(k_{\mathrm{sv}}=1000\right.$ and $\left.k_{\mathrm{ag}}=1000\right)$. It is important to note that in Fig. 10, the phytoplankton concentration is not the same scale for all panels; white corresponds to a maximum concentration of 1000

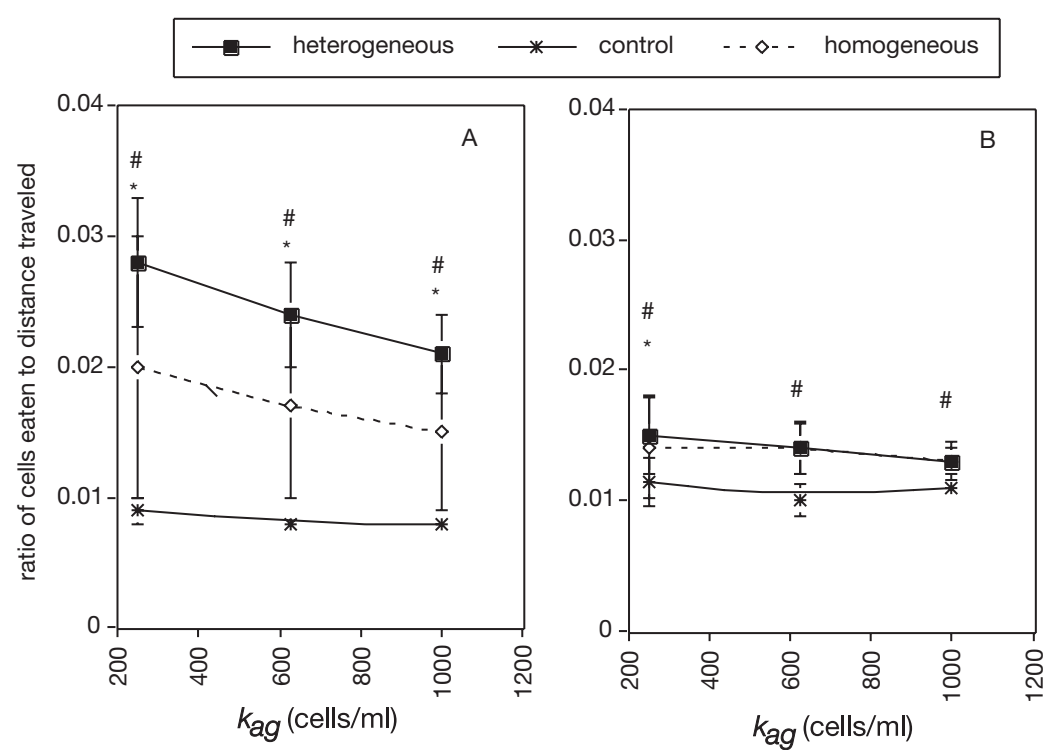

Fig. 9. Mean CEDT (cells eaten: distance traveled) $(\mathrm{n}=100)$ versus $k_{\mathrm{ag}}$. Error bars \pm 1 SD. $k_{\mathrm{sv}}=250$ cells per grid square. ${ }^{*}$ Significant differences $(\mathrm{p}<0.05$, paired $t$-test with unequal variance) between heterogeneous and homogeneous layers and \# between heterogeneous layer and control 


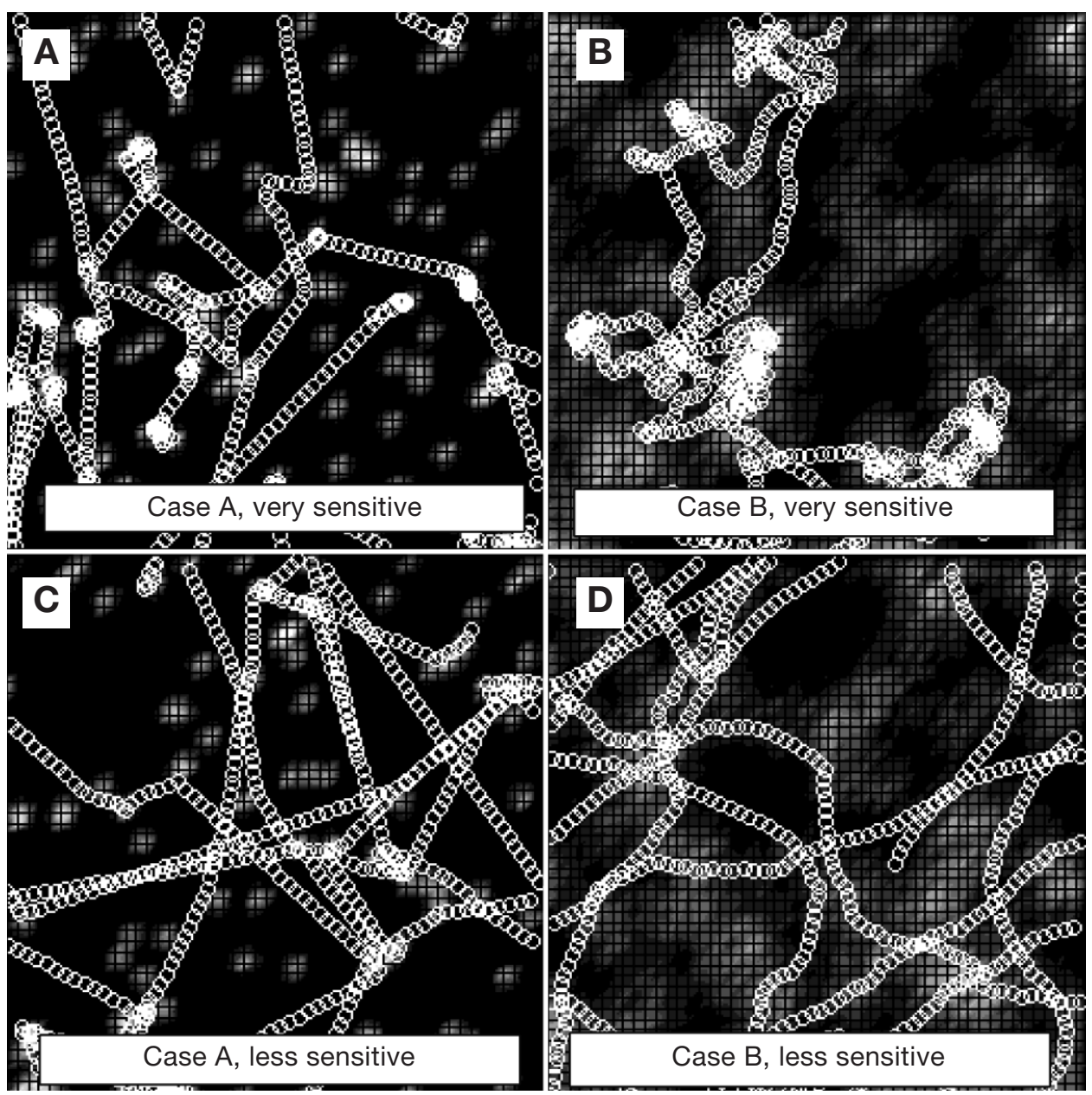

Fig. 10. Tracks for 4 individual copepods (1 track per panel) over $50 \times 50 \mathrm{~cm}$ area, overlaid on phytoplankton distribution. Each track for $600 \mathrm{~s}$ ( 600 iterations). White circles, position of copepod at $1 \mathrm{~s}$ intervals. Maximum phytoplankton concentration (white): case A $(\mathrm{A}, \mathrm{C}) 1000$ cells $\mathrm{ml}^{-1}$; case B $(\mathrm{B}, \mathrm{D}) 450 \mathrm{cells} \mathrm{m}^{-1}$. $(\mathrm{A}, \mathrm{B})$ Very sensitive swimming response $\left(k_{\mathrm{sv}}=250, k_{\mathrm{sv}}=250\right)$, $(\mathrm{C}, \mathrm{D})$ less sensitive response $\left(k_{\mathrm{sv}}=1000, k_{\mathrm{ag}}=1000\right)$

cells ml $\mathrm{m}^{-1}$ in Fig. 10A,C, but only 450 cells ml $\mathrm{ml}^{-1}$ in Fig. 10B,D. In all 4 examples, copepods travel within and between several different individual patches within the $600 \mathrm{~s}$; a short time compared to the $21600 \mathrm{~s}$ total simulation time. When patches are intense (Fig. $10 \mathrm{~A}, \mathrm{C})$ the copepods spend more time 'lost' between the patches. However, when they do encounter a patch, they stay there longer and feed at much higher rates, because the concentration of food within the patch is so much higher - patch center concentrations are between 800 and 1000 cells $\mathrm{ml}^{-1}$ when patches are intense, versus 400 to 450 cells $\mathrm{ml}^{-1}$ when they are diffuse. In addition, the copepods take more time to penetrate the center of a patch when the patch is more diffuse because the width of the patch is large compared to the step length of the copepod, such that it is more likely that the copepod may randomly change direction and exit the patch.

\section{DISCUSSION}

When thin horizontal layers are not homogeneous but are composed of smaller patches there can be a large difference in the foraging success of herbivorous copepods that actively move around as they search for food. The biggest difference in foraging efficiency between the patchy and homogeneous layer scenarios occurred when patches were small and intense. The results of this modeling exercise suggest that if we assume patchy thin layers are homogeneous, as we might when reconstructing the environment by averaging single vertical profiles of fluorescence, we will greatly underestimate the feeding rates of certain planktonic copepods. For the patchiest case A, the homogeneous layer approximations led to $\sim 30 \%$ decrease in the average amount of food ingested. Alternatively, it is possible that thin layers are not 
always patchy but are homogeneous at the microscale. When this is the case, the large decrease in ingestion rate could potentially be fatal to smaller copepods and copepods that do not store lipid reserves, such as the genus Acartia (Dagg 1977). Copepods that are omnivorous could switch to microzooplankton prey when phytoplankton is limiting in this fashion. Patchiness of food may be absolutely necessary for the survival of some copepods when food is limiting, if they cannot switch to an alternative feeding mode. There was also a large difference in the foraging success of the copepods between the 2 different heterogeneous cases - the average number of cells eaten was nearly double in case $\mathrm{A}$, the environment with more intense patches - although the total available food was similar between the 2 environments. These 2 patch environments differed in the maximum concentration of food within a patch, which was a function of the width of the patch; patch widths varied by only a few centimeters between the 2 cases. In combination, these results suggest that patchiness needs to be sampled close to the same scale as the copepod's maximum step length, because using spatially averaged phytoplankton concentrations to estimate copepod feeding can be highly misleading.

Even if starvation does not occur, the egg production rate of a copepod will decrease when the environment is not patchy and food is limiting. Kleppel (1992) used field data to correlate egg production with daily ingestion rate for Acartia tonsa. The correlation coefficient was poor since the data were highly scattered, but based on that relationship, the $30 \%$ decrease in ingestion rate seen in the current study could lead to as much as a $50 \%$ decrease in egg production. As a lower boundary, a laboratory study by Kiørboe et al. (1985) showed that the egg production of $A$. tonsa decreased by at least as much as $20 \%$ given a $30 \%$ decrease in ingestion rate (measured in units of $\mu \mathrm{gC}$ ). These levels of reduction of egg production are quite large, and further support the idea that without food being concentrated into small, more intense patches, some copepods may not produce enough eggs to persist. This being the case, foraging characteristics that allow copepods to take advantage of food patches should be highly selected for, while other copepods that are not adapted to deal with patchiness may be out-competed. Alternatively, copepods may switch their foraging mode completely, perhaps to 'ambush predation'-as seen in some Acartia species (Kiørboe et al. 1996) - in order to avoid problems related with actively foraging in patchy environments.

When food is not patchy, a copepod experiences a decreased ingestion rate, and would therefore have to increase the time it spends foraging and feeding in order to achieve the same total daily ingestion as when food is patchily distributed. This may be an even greater problem for copepods than decreased egg production for 2 reasons, both related to predation risk. First, there may be an increase in predation risk if the swimming activities associated with feeding bouts make a copepod a more attractive target to a predator (Buskey et al. 1993, Buskey 1994). If this is true, then it would be advantageous for a copepod to quickly fill its gut, cease feeding activity, and perhaps even become passive so as not to attract either visual or mechanosensory predators. In a laboratory study, Saiz et al. (1993) found that $A$. tonsa spent less time within food patches when predators were present, suggesting that feeding activity is linked to predation risk. The second way in which decreased ingestion rate can lead to higher predation risk is through an increase in the encounter rate with predators. In the current model, ingestion rate and swimming speed are coupled, such that when swimming speed is high, ingestion rate is low. Based on the difference in the average swimming speed of individuals between the patchy and homogeneous layer scenarios in case $\mathrm{A}$, and assuming a predator speed approximately twice that of the copepod, encounter rate would be around 5\% higher for copepods in the homogeneous layer scenario (calculated using the encounter model of Evans 1989). This may seem like a small increase in predation risk relative to the large decrease in ingestion rate; however, a decrease in ingestion rate may not always be fatal, whereas a single encounter with a predator can be. Thus, predator avoidance can be an important factor controlling the behavior of an organism, and may, or may not, select for the same traits as those for optimally finding food.

In the current study, there was little difference in foraging efficiency when the parameter controlling the turn angle versus food concentration was changed (Figs. $7 \&$ 9). On the other hand, changing the step length parameter $\left(k_{\mathrm{sv}}\right)$ had a large effect on the model results in both cases A and B (Figs. 6 \& 8). For a $400 \%$ increase in $k_{\text {ag }}$ there was a decrease of between 6 and $28 \%$ in CEDT, whereas for a $400 \%$ increase in $k_{\mathrm{sv}}$, the decrease in CEDT was anywhere between 33 and $65 \%$; changing step length sensitivity is more than twice as important as turn angle sensitivity for increasing foraging efficiency. This supports the results of an earlier modeling study by Doucet \& Drost (1985), which found that klinokinesis - varying turn angle as a function of resource density - had little if any effect on the distribution of individuals, while orthokinesisvarying step length as a function of resource densitycould lead to significant concentration of individuals within high resource areas. Their model, however, was run with only one particular 2-D patch environment (i.e. a perfect 'checkerboard' pattern). In this study, case A 
showed a slight decreasing trend in CEDT as $k_{\text {ag }}$ increased (Fig. 9A). From their modeling work examining the diffusion of predators through a patchy environment, Davis et al. (1991) suggested that changing turn angle as a function of food concentration should affect the rate of dispersion through the environment, but would not by itself lead to aggregation. If this is true, then it may be that for case $A$, where there was the largest distance between patch edges, changing the sensitivity of the turn angle parameter affected the rate of movement through patches, and therefore affected the retention rate within a patch and ultimately CEDT. For case B, the effects may not have been noticeable because the distance between patch edges was shorter.

Unlike the turning response, changing the sensitivity of the copepods' step length response had a large effect on foraging efficiency. For the different cases A and $\mathrm{B}$, there was a general decrease in foraging efficiency as the sensitivity of a copepod's step length response to food concentration decreased (i.e. $k_{\mathrm{sv}}$ increased). This was also found in a modeling study by Leising \& Franks (2000), which used the same parameterization of step length versus food concentration as the current model, although the movement of the simulated copepods was limited to the vertical dimension. Leising \& Franks' (2000) results showed that while decreasing the sensitivity of a copepod's step length to food concentration led to a decrease in foraging efficiency, it led to an increase in the rate at which the copepod moved through its environment. This can clearly be seen by comparing Fig. 10A,B (sensitive copepods) with Fig. 10C,D (less sensitive copepods); the less sensitive copepods travel much more extensively through the environment. Although it was not explicitly tested in the 2-D model used here, the conclusion from Leising \& Franks' (2000) 1-D model should hold; there is a trade-off between net foraging efficiency and movement rate through an environment. Moving through the environment rapidly to sample a larger amount of the available patches is important when first entering a new environmentit prevents the copepod from becoming 'stuck' in lowconcentration patches near the periphery. This may be especially relevant to herbivorous copepods that migrate vertically each night into the upper water column to feed, and will therefore always encounter lower phytoplankton concentrations before reaching the sub-surface chlorophyll maximum.

Even though decreasing the sensitivity of a copepod's functional response, or assuming that layers were homogeneous, led to a decrease in foraging efficiency, it was always higher than the random controls. This is an important result, because it suggests that even when an environment is not very patchy, it is still advantageous to have a set behavior of some kind, rather than to behave randomly. For the current study, a type of area-restricted search was chosen as the behavior. This behavior has been examined in many different taxa and appears to be a robust way to find and remain within high resource areas. According to the results presented here, it should also work well for herbivorous copepods that live in predictably patchy environments. In their 1-D model, Leising \& Franks (2000) found that there was not a large increase in the mean foraging efficiency of copepods using arearestricted search versus random behavior, but that there was a large increase in the variance of foraging efficiency-more than $30 \%$ of the population had a higher CEDT ratio than any of the randomly behaving individuals. When expanding the model to 2-D, variance of foraging efficiency for the area-restricted searching copepods increased over the 1-D model, but there was also a significant increase in the mean for the population over the controls.

The increased difference in foraging efficiency between the copepods using area-restricted search and the controls when going from 1-D to 2-D can best be explained by considering the rate of motion of the copepods through space. For the control copepods in both cases, their motion can be modeled as a random walk. Following arguments in Berg (1983), the rms displacement $\left\langle r^{2}\right\rangle^{1 / 2}$ over time $t$ of a particle exhibiting a random walk will be a factor of 2 greater in 2-D than in 1-D space. This increase in displacement over time for the 2-D controls means that each copepod samples more of the environment, thus differences between individuals in ingestion rate due to the spatial variability of food concentration will be averaged out. As seen in the current 2-D model, with the subsequent decrease in the variance of food eaten in the control population, it becomes easier to statistically differentiate between the mean value of food ingested by the copepod populations using random and set behavior. Besides this difference in the control populations between 2-D and 1-D space, the copepods using arearestricted search in 2-D decrease their rms displacement-effectively their 'diffusivity' — to a greater extent than their 1-D counterparts, because in 2-D the copepods change not only their step lengths, but increase the tortuosity of their paths as well. Taking these facts into account, if the model were expanded to 3-D space there should be a further increase in the difference in foraging success between control and area-restricted searching copepods. For the controls, the rms displacement will increase by an additional factor of 1.2 for the 3-D case over the 2-D case (Berg 1983), while the arearestricted searching copepods will decrease their diffusivity because they have higher-dimensionality paths.

An appealing aspect of choosing area-restricted search behavior for a modeling study such as the cur- 
rent one, is that while it can lead to complicated distributions which mimic other theoretically derived optimal distributions, such as the Ideal-Free Distribution (Fretwell \& Lucas 1970), it does not require complicated actions by the copepod (Leising \& Franks 2000). In fact, for some copepods, which feed and swim using some of the same appendages, there is no choice but to slow down when higher concentrations of food are encountered. It also appears that area-restricted search confers a greater advantage as the dimensionality and complexity of the environment increases. As mentioned earlier, there have been some laboratory studies showing that copepods exhibit movements characteristic of an area-restricted search. However, further studies are necessary to quantify the exact responses of swimming speeds and turning angles versus food concentration for particular species of copepods. Another important issue that was not addressed in the current model was satiation of the copepods feeding response. Many species of copepods could fill their guts in a much shorter time than the $6 \mathrm{~h}$ simulated here, and would probably change their feeding and swimming behavior at that point. This could have a large impact on the results of the current model, and will hopefully be addressed in future modeling work as more laboratory measurements of such Effects are examined. With such information, it should be possible to use models such as SEARCH to make quantitative predictions of copepod growth and microscale distributions given real field-sampled phytoplankton distributions.

Acknowledgements. This work was supported by the US National Science Foundation OPP-9525803, Office of Naval Research N00014-95-1-0189 and N00014-95-1-0764 to Peter J. S. Franks, and a Postdoctoral fellowship from the University of Washington, School of Fisheries and Ocean Science to A.W.L. I would like to thank Peter J. S. Franks for advice and comments on this manuscript, and also the other members of the Franks Lab group for discussions concerning this work. Comments from 3 anonymous reviewers also helped to improve this contribution considerably. Special thanks to Jules Jaffe and Dave Zawada for letting me speculate wildly with their data from both the LUMIS and OSST systems.

\section{LITERATURE CITED}

Benedix JH Jr (1993) Area-restricted search by the plains pocket gopher (Geomys bursarius) in tallgrass prairie habitat. Behav Ecol 4:318-324

Berg HC (1983) Random walks in biology. Princeton University Press, Princeton, NJ

Bjornsen PK, Nielsen TG (1991) Decimeter scale heterogeneity in the plankton during a pycnocline bloom of Gyrodinium aureolum. Mar Ecol Prog Ser 73:263-267

Bovet P, Benhamou S (1988) Spatial analysis of animals' movements using a correlated random walk model. J Theor Biol 131:419-433
Buskey EJ (1984) Swimming pattern as an indicator of the roles of copepod sensory systems in the recognition of food. Mar Biol 79:1165-1175

Buskey EJ (1994) Factors affecting feeding selectivity of visual predators on the copepod Acartia tonsa: locomotion, visibility and escape responses. Hydrobiologia 292/293: 447-453

Buskey EJ, Coulter C, Strom S (1993) Locomotory patterns of microzooplankton: potential effects on food selectivity of larval fish. Bull Mar Sci 53:29-34

Cassie RM (1959) Micro-distribution of plankton. NZ J Sci 2: 398-409

Cassini MH, Föger B (1995) The effect of food distribution on habitat use of foraging hedgehogs and the ideal nonterritorial despotic distribution. Acta Oecol 16:657-669

Cowles TJ, Desiderio RA, Neuer S (1993) In situ characterization of phytoplankton from vertical profiles of fluorescence emission spectra. Mar Biol 115:217-222

Cowles TJ, Desiderio RA, Carr ME (1998) Small-scale planktonic structure: persistence and trophic consequences. Oceanography 11:4-9

Cullen JJ, Eppley RW (1981) Chlorophyll maximum layers of the southern California bight and possible mechanisms of their formation and maintenance. Oceanol Acta 4:23-32

Dagg M (1977) Some effects of patchy food environments on copepods. Limnol Oceanogr 22:99-107

Davis CS, Flierl GR, Wiebe PH, Franks PJS (1991) Micropatchiness, turbulence and recruitment in plankton. J Mar Res 49:109-151

Derenbach JB, Astheimer H, Hansen HP, Leach H (1979) Vertical microscale distribution of phytoplankton in relation to the thermocline. Mar Ecol Prog Ser 1:187-193

Doucet PG, Drost NJ (1985) Theoretical studies on animal orientation II. Directional displacement in kineses. J Theor Biol 117:337-361

Durbin EG, Durbin AG (1992) Effects of temperature and food abundance on grazing and short-term weight change in the marine copepod Acartia hudsonica. Limnol Oceanogr 32:361-378

Evans GT (1989) The encounter speed of moving predator and prey. J Plankton Res 11:415-417

Ferran A, Dixon FG (1993) Foraging behavior of ladybird larvae (Coleoptera: Coccinellidae). Eur J Entomol 90: 383-402

Fretwell SD, Lucas HL (1970) On territorial behavior and other factors influencing habitat distribution in birds. I. Theoretical development. Acta Biotheor 19:16-36

Gerritsen J, Strickler JR (1977) Encounter probabilities and community structure in zooplankton: a mathematical model. J Fish Res Board Can 34:73-82

Haskell DG (1997) Experiments and a model examining learning in the area-restricted search behavior of ferrets (Mustela putorius furo). Behav Ecol 8:448-455

Holling CS (1966) The functional response of invertebrate predators to prey density. Mem Entmol Soc Can 48:1-86

Jaffe JS, Franks PJS, Leising AW (1998) Simultaneous imaging of phytoplankton and zooplankton distributions. Oceanography 11:1-5

Kareiva P (1982) Experimental and mathematical analyses of herbivore movement: Quantifying the influence of plant spacing and quality on foraging discrimination. Ecol Monogr 53:261-282

Kareiva P, Odell G (1987) Swarms of predators exhibit 'preytaxis' if individual predators use area-restricted search. Am Nat 130:233-270

Kiørboe T, Mohlenberg F, Hamburger K (1985) Bioenergetics of the planktonic copepod Acartia tonsa: relation between 
feeding, egg production and respiration, and composition of specific dynamic action. Mar Ecol Prog Ser 26:85-97

Kiørboe T, Saiz E, Viitasalo M (1996) Prey switching behavior in the planktonic copepod Acartia tonsa. Mar Ecol Prog Ser 143:65-75

Kleppel GS (1992) Environmental regulation of feeding and egg production by Acartia tonsa off southern California. Mar Biol 112:57-65

Leising AW (2000) Copepod foraging in thin layers using SEARCH (simulator for exploring area-restricted search in complex habitats). Marine Models OnLine (in press)

Leising AW, Yen J (1997) Spacing mechanisms within light-induced copepod swarms. Mar Ecol Prog Ser 155:127-135

Leising AW, Franks PJS (2000) Copepod vertical distribution within a spatially variable food source: a simple foragingstrategy model. J Plankton Res 22:999-1024

McAlice BJ (1970) Observations on the small-scale distribution of estuarine phytoplankton. Mar Biol 7:100-111

Mitchell JG, Fuhrman JA (1989) Centimeter scale vertical heterogeneity in bacteria and chlorophyll a. Mar Ecol Prog Ser 54:141-148

Morris MJ, Gust G, Torres JJ (1985) Propulsion efficiency and cost of transport for copepods: a hydrodynamical model of crustacean swimming. Mar Biol 86:283-295

Morris MJ, Kohlage K, Gust G (1990) Mechanics and energetics of swimming in the small copepod Acanthocyclops robustus (Cyclopoida). Mar Biol 107:83-91

Mullin MM, Stewart EF, Fuglister FJ (1975) Ingestion by planktonic grazers as a function of concentration of food. Limnol Oceanogr 20:259-262

Owen RW (1989) Microscale and finescale variations of small plankton in coastal and pelagic environments. J Mar Res 47:197-240

Owen RW, Gianesella-Galvao SF, Kutner MBB (1992) Dis-

Editorial responsibility: Thomas Kiørboe (Contributing Editor), Charlottenlund, Denmark crete, subsurface layers of the autotrophic ciliate Mesodinium rubrum off Brazil. J Plankton Res 14:97-105

Piontkovskii SA, Petipa TS (1976) Quantitative description of the behavior of copepod Acartia clausi during feeding on algae. Sov J Mar Biol 2:40-46

Saiz E, Alcaraz M (1992) Free-swimming behavior of Acartia clausi (Copepoda: Calanoida) under turbulent water movement. Mar Ecol Prog Ser 80:229-236

Saiz E, Tiselius P, Jonsson PR, Verity P, Paffenhöfer GA (1993) Experimental records of the effects of food patchiness and predation on egg production of Acartia tonsa. Limnol Oceanogr 38:280-289

Smith JNM (1974) The food searching behavior of two European thrushes. II: The adaptiveness of the search patterns. Behavior 49:1-61

Tinbergen N, Impekoven M, Franck D (1967) An experiment on spacing-out as a defence against predation. Behaviour 28:307-321

Tiselius P (1992) Behavior of Acartia tonsa in patchy food environments. Limnol Oceanogr 37:1640-1651

Tiselius P, Jonsson PR (1990) Foraging behavior of six calanoid copepods: observations and hydrodynamic analysis. Mar Ecol Prog Ser 66:23-33

Tiselius P, Jonsson PR, Verity PG (1993) A model evaluation of the impact of food patchiness on foraging strategy and predation risk in zooplankton. Bull Mar Sci 53:247-264

Tiselius P, Nielsen G, Nielsen TG (1994) Microscale patchiness of plankton within a sharp pycnocline. J Plankton Res $16: 543-554$

Uchima M, Hiramo R (1988) Swimming behavior of the marine copepod Oithona davise: internal control and search for environment. Mar Biol 99:47-56

Zach R, Falls BJ (1977) Influence of capturing prey on subsequent search in the ovenbird (Aves: Parulidae). Can J Zool 55:1958-1969

Submitted: September 9, 1999; Accepted: October 11, 2000

Proofs received from author(s): May 30, 2001 